\title{
PENGARUH PENYANGRAIAN BIJI KAKAO NON FERMENTASI DENGAN SISTEM UAP PANAS TERHADAP KANDUNGAN POLIFENOL, KATEKIN, DAN RESIDU PESTISIDA KAKAO BUBUK
}

\author{
The Effect of Steam Blanching Roasting Method of Non Fermented Cocoa Beans to \\ Cocoa Powder Polyphenol, Catechin and Pesticides Residues Content
}

\author{
Wahyuni, Rosniati, Medan Yumas, Melia Ariyanti, dan Dwi Indriana \\ Balai Besar Industri Hasil Perkebunan \\ Jl. Prof. Dr. Abdurrahman Basalamah No.28 Makassar 90231 \\ e-mail: wahyunibakri24@gmail.com
}

\begin{abstract}
This study aims to determine the content of polyphenols, catechins, and pesticide residues in cocoa powder. Cocoa powder made from fresh cocoa beans that processed through steam blanching method then dried by drying in protected sunlight, then roasted by the hot steam method using water bath at $80^{\circ} \mathrm{C}$ for 30 minutes and without roasting. The scope of this research is Sangrai Cocoa Beans (BS) and Cocoa Beans without Roast (BTS). The results showed that cocoa powder produced from roasted cocoa beans (RB) and without roasting (URB) had total polyphenol content of $6,89 \%$ and $9,42 \%$, respectively. Catechin compounds in cocoa powder from RB and URB are $6.626 \mathrm{~g} / 100 \mathrm{~g}$ and $6.335 \mathrm{~g} / 100 \mathrm{~g}$, respectively. Pesticide residues from all cocoa powder analyzed were not detected, so cocoa powder produced from this study was safe from pesticides.
\end{abstract}

Keywords: Cocoa beans, cocoa powder, catechins, polyphenols, pesticide residues

\begin{abstract}
Abstrak: Penelitian ini bertujuan untuk mengetahui kandungan polifenol, katekin, dan residu pestisida pada kakao bubuk. Biji kakao basah diblanching menggunakan air panas, kemudian dikeringkan dengan cara dijemur pada sinar matahari terlindung. Biji kakao kering disangrai dengan metode uap air panas menggunakan waterbath pada suhu $80^{\circ} \mathrm{C}$ selama 30 menit. Ruang lingkup pada penelitian ini yaitu Biji Kakao Sangrai (BS) dan Biji Kakao Tanpa Sangrai (BTS). Hasil penelitian menunjukkan bahwa kakao bubuk yang dihasilkan dari biji kakao sangrai (BS) mempunyai kandungan senyawa total polifenol $6,89 \%$ sedangkan kakao bubuk tanpa sangrai (BTS) mempunyai kandungan total polifenol $9,42 \%$. Senyawa katekin pada kakao bubuk dari biji kakao sangrai (BS) $6,335 \mathrm{~g} / 100 \mathrm{~g}$, sedangkan biji kakao tidak sangrai (BTS) 6,626 g/100g. Residu pestisida dari semua kakao bubuk yang dianalisis tidak ada yang terdeteksi, sehingga kakao bubuk yang dihasilkan dari penelitian ini aman dari pestisida.
\end{abstract}

Kata Kunci: Biji kakao, kakao bubuk, katekin, polifenol, residu pestisida.

\section{PENDAHULUAN}

Kakao (Theobroma cacao $L$ ) yang merupakan bahan dasar pembuatan makanan dan minuman cokelat mengandung senyawa bioaktif yang bermanfaat mencegah terjadinya penimbunan kolesterol pada dinding pembuluh darah dan juga mengandung antioksidan berupa flavonoid yang dapat mengendalikan radikal bebas penyebab kanker (Sianturi, 2003). Hasil penelitian Crozier et al. (2011), menyebutkan bahwa kakao mengandung senyawa polifenolik dengan konsentrasi yang cukup tinggi terutama flavanol. Senyawa ini banyak dikaitkan dengan sejumlah manfaat kesehatan dalam memperbaiki aliran darah dan elastisitas pembuluh darah, menurunkan tekanan darah, mencegah penggumpalan darah, menstimulasi sintesis oksida nitrit, dan sebagai anti inflamasi.

Salah satu manfaat kesehatan dari polifenol kakao yaitu mempunyai kemampuan untuk melindungi saluran pernafasan dan juga berperan penting sebagai penanda (marker) peradangan dalam atherosclerosis (Khan et al., 2014). Barberan et al. (2007) menyatakan responden yang meminum kakao bubuk tinggi kandungan flavonoid mempunyai kadar epikatekin glucuronide lima kali lipat lebih tinggi, sehingga mempunyai efek kesehatan yang lebih kuat. Penelitian Ramlah (2014) menyebutkan bahwa suhu penyangraian berpengaruh terhadap mutu cokelat sebagai makanan kesehatan. Cokelat 
yang diolah menjadi makanan kesehatan ternyata dapat menurunkan kadar kolesterol darah secara signifikan pada model mencit hiperkolesterolemia. Lebih lanjut Yuliatmoko et al. (2008) menyatakan bahwa kakao bubuk dapat meningkatkan sistem antioksidan plasma sehingga bermanfaat bagi kesehatan.

Kombinasi suhu yang tinggi dan lamanya waktu penyangraian serta adanya air adalah kondisi yang penting untuk diperhatikan. Penyangraian biji dengan suhu yang tinggi dan waktu yang lama akan mengurangi kadar flavonoid karena terjadi degradasi yaitu oksidasi enzimatis maupun non enzimatis. Panas yang digunakan dalam penyangraian dapat menyebabkan komponen flavonoid teroksidasi, diuapkan, dan atau senyawa ini diubah dan kuantitasnya berkurang (Barberan, 2007). Pengolahan biji kakao yang dapat merusak polifenol antara lain suhu, perubahan kimia dan waktu yang mempengaruhi nilai polifenol dalam produk bervariasi. Proses blanching bertujuan untuk menonaktifkan enzim polifenol oksidase (PPO), biji kakao diblanching menggunakan uap air panas (steaming) suhu $90^{\circ} \mathrm{C}$ selama 5 menit (Barberan et al., 2007). Hal ini bertujuan untuk menghentikan proses oksidasi polifenol. Selanjutnya penyangraian biji kakao kering menggunakan suhu rendah dan waktu pendek (Low Temperature Short Time) untuk meminimalisir berkurangnya kandungan flavonoid termasuk polifenol dalam produk akhir.

Kandungan senyawa polifenol yang terdapat pada biji kakao segar dan belum dilakukan proses fermentasi adalah 12-18\% (Cooper et al.,2007; Acker et al., 2013). Kandungan senyawa polifenol pada biji kakao meliputi katekin 33-42\%, leukosianidin 23-25\%, dan antosianin 5\%. Sedangkan pada kakao bubuk bebas lemak mengandung $5-18 \%$ senyawa polifenol (Kusuma et al., 2013). Senyawa polifenol merupakan senyawa kimia yang mempunyai sifat antioksidan, yang sangat penting dalam perannya menyehatkan tubuh manusia (Crozier et al., 2011).
Kakao bubuk merupakan salah satu produk olahan dari biji kakao fermentasi atau tanpa fermentasi yang diperolah melalui proses penyangraian, alkalisasi, pengeluaran kulit ari, pemastaan, pemisahan lemak dan bungkil. Bungkil kakao yang telah dihaluskan dan diayak dengan ayakan 200 mesh disebut kakao bubuk. Selain kandungan senyawa polifenol, senyawa asam amino dalam kakao juga di pengaruhi oleh proses fermentasi, pengeringan dan proses thermal lainnya (Rosniati et al., 2018)

Kakao bubuk yang mempunyai manfaat kesehatan diolah dari biji kakao non fermentasi dikarenakan kandungan flavonoid dan polifenolnya yang lebih tinggi. Kegunaan kakao bubuk non fermentasi ini lebih sedikit dibandingkan kakao bubuk fermentasi karena permintaan pasar yang spesifik (segmented) terutama untuk konsumen yang lebih peduli pada kesehatan tubuh. Kakao bubuk diproses dari biji kakao non fermentasi sehingga dapat lebih diekspos sifat fungsionalnya. Kakao bubuk yang tinggi kandungan flavonoidnya diperlukan karena keberadaan flavonoid dalam kakao istimewa. Flavonoid kakao terdiri atas 4 stereoisomer flavanol (+)-katekin; (-)-katekin; (+)-epikatekin dan (-)-epikatekin. (-)-epikatekin inilah yang paling banyak terdapat pada flavonoid kakao dan memiliki bioavailabilitas yang tinggi sehingga mudah diserap tubuh (Hui, 1996).

Kakao bubuk terkenal dengan kandungan polifenol dan flavonoid tinggi yang bermanfaat bagi kesehatan manusia. Pengembangan teknologi proses pengolahan bubuk cokelat kaya flavonoid diharapkan mampu meningkatkan mutu kakao bubuk non fermentasi yang dihasilkan untuk bahan baku pembuatan minuman cokelat fungsional. Penelitian ini bertujuan untuk mengetahui kandungan polifenol, katekin, dan residu pestisida pada kakao bubuk

\section{METODOLOGI}

\section{Bahan dan Alat}

Bahan baku yang digunakan pada penelitian meliputi buah kakao dari Kabupaten Bantaeng. Sedangkan 
peralatan yang digunakan adalah pisau untuk membelah buah, depulper (pemisah pulp/lendir), kompor dan dandang untuk proses blanching biji, waterbath untuk menyangrai biji kakao dengan suhu rendah, alat counching, alat press lemak kakao, timbangan digital, thermometer, talang, baskom, baki stainless steel, kemasan plastik, alumunium foil, spatula, alat uji GC, HPLC, spektrofotometri, AAS, dan alat penolong lainnya.

\section{Metode Penelitian}

Penelitian ini dilakukan dalam 2 tahap yaitu tahap pertama penyiapan bahan baku (biji kakao) dan tahap kedua adalah penyiapan kakao bubuk. Pengembangan teknologi proses pengolahan kakao bubuk kaya flavonoid dirancang dengan metode eksperimen pengolahan biji kakao menjadi kakao bubuk yang masih memiliki kadar flavonoid tinggi dengan perlakuan metode blanching dengan steaming (uap air panas), pengeringan biji kakao, dan pemanasan (sangrai) menggunakan metode Low Temperature Short Time memakai alat waterbath yang sudah dimodifikasi disesuaikan dengan proses penyangraian biji kakao menggunakan alat Fluidized Bed Roasting.

\section{Penyiapan Biji Kakao}

Biji kakao dikeluarkan dari buah, dipisahkan biji dari empulurnya, kemudian dimasukkan ke dalam alat depulper (pemisah pulp/lendir kakao). Biji kakao yang telah dikeluarkan pulpnya diblanching dengan uap panas dengan tujuan untuk menginaktifkan enzim polifenol oksidase. Selanjutnya biji kakao basah dijemur pada sinar matahari secara terlindung. Penjemuran dilakukan selama kurang lebih 5 hari atau sampai kadar air sekitar 7\%. Biji kakao kering siap untuk dibuat kakao bubuk.

\section{Penyiapan Kakao Bubuk}

Biji kakao kering dibagi menjadi dua kelompok. Kelompok pertama biji kakao tidak disangrai (BTS), dan kelompok ke dua biji kakao disangrai dengan metode uap air panas yaitu menggunakan waterbath dengan suhu $80^{\circ} \mathrm{C}$ selama 30 menit (BS). Selanjutnya biji kakao dipisahkan kulit ari dan nib. Nib yang diperoleh dicounching menjadi pasta kakao. Pasta kakao dipress untuk memisahkan lemak dan bungkil (cake). Selanjutnya bungkil kakao dihaluskan menggunakan blender kemudian diayak dengan ukuran mesh 200 untuk memperoleh kakao bubuk.

\section{Metode Analisis}

Analisis kakao bubuk dilakukan terhadap parameter polifenol dan katekin dengan metode HPLC sedangkan residu pestisida dengan metode GC-ECD. Analisis data dilakukan secara deskriptif.

\section{HASIL DAN PEMBAHASAN}

Kakao bubuk yang dihasilkan pada penelitian ini diperoleh dari biji kakao yang telah disangrai dengan uap panas menggunakan waterbath (BS) dan dari biji kakao yang tidak disangrai (BTS). Hasil analisis kakao bubuk dapat dilihat pada Tabel 1.

Tabel 1. Hasil analisis polifenol, katekin, dan residu pestisida kakao bubuk

\begin{tabular}{lcc}
\hline \multicolumn{1}{c}{ Parameter } & Kakao bubuk Sangrai (BS) & Kakao bubuk Tidak Sangrai (BTS) \\
\hline Polifenol & $6,89 \%$ & $9,42 \%$ \\
Katekin & $6,335 \mathrm{~g} / 100 \mathrm{~g}$ & $6,626 \mathrm{~g} / 100 \mathrm{~g}$ \\
Residu Pestisida & TTD & TTD \\
\hline
\end{tabular}




\section{Polifenol}

Hasil penelitian menunjukkan bahwa kakao bubuk yang dihasilkan dari biji kakao sangrai (BS) mempunyai kandungan total polifenol $6,89 \%$, sedangkan kakao bubuk tidak sangrai (BTS) mempunyai kandungan total polifenol 9,42\% (Tabel 1).

Tingginya kandungan total polifenol pada kakao bubuk dengan perlakuan penyangraian dengan metode uap panas, disebabkan karena degradasi struktur seluler selama penyangraian dan menyebabkan keluarnya senyawa fenolik yang terikat (Oracz dan Nebesny, 2016).

Kulit biji kakao tanpa fermentasi mengandung polifenol yang terdapat pada biji kakao belum mengalami difusi dari sel penyimpanan dan hal ini yang mengakibatkan kenaikan kandungan fenolik total pada penyangraian derajat sedang suhu $140^{\circ} \mathrm{C}$ dan derajat berat suhu $190^{\circ} \mathrm{C}$ karena terlepasnya ikatan senyawa fenolik dari matrik sel (Suazo et al., 2013). Peningkatan kandungan fenolik total juga bisa disebabkan karena degradasi antosianin menjadi monomernya (Misnawi et al., 2005).

Tingginya kandungan total polifenol yang dihasilkan pada penelitian ini disebabkan perlakuan biji kakao yang digunakan tanpa fermentasi dengan perlakuan metode blanching dengan steaming (uap panas), bertujuan untuk menonaktifkan enzim polifenol oksidase (PPO) pengeringan biji kakao, dan pemanasan (sangrai) menggunakan metode uap panas menggunakan alat waterbath yang sudah dimodifikasi disesuaikan dengan proses penyangraian biji kakao menggunakan alat Fluidized Bed Roasting sehingga dapat mempertahankan kandungan polifenol pada kakao bubuk.

Menurut Harrington (2011) adanya kandungan senyawa polifenol dalam produk cokelat akan memberikan keuntungan bagi peningkatan kualitas produk tersebut, dikarenakan senyawa polifenol mempunyai kemampuan antioksidan yang dapat mencegah terjadinya kerusakan makanan akibat peristiwa oksidasi terhadap lemak kakao yang dapat menyebabkan ketengikan (rancidity). Dengan demikian akan meningkatkan keawetan maupun waktu simpan dari produk makanan cokelat tersebut.

\section{Katekin}

Katekin adalah segolongan metabolit sekunder yang secara alami dihasilkan oleh tumbuhan dan termasuk dalam golongan flavonoid. Senyawa ini memiliki aktivitas antioksidan karena gugus fenol yang dimilikinya. Strukturnya memiliki dua gugus fenol (cincin-A dan -B) dan satu gugus dihidropiran (cincin-C). Karena memiliki lebih dari satu gugus fenol, senyawa katekin sering disebut senyawa polifenol (Nazaruddin, et al.,2006)

Hasil Analisa katekin kakao bubuk pada Tabel 1, menunjukkan bahwa katekin pada kakao bubuk dari biji kakao sangrai $6,335 \mathrm{~g} / 100 \mathrm{~g}$ sedangkan katekin kakao bubuk dari biji kakao tidak sangrai 6,626 g/100 g. Senyawa katekin yang terdapat pada kakao bubuk merupakan kandungan senyawa total polifenol yang dapat dipertahankan dengan cara fluidized.

Biji buah kakao mengandung cukup tinggi senyawa yang aktif sebagai antioksidan, diantaranya adalah katekin 33$42 \%$, leukosianidin $23-25 \%$, dan antosianin $5 \%$. Sedangkan pada biji kakao bubuk bebas lemak mengandung $5-18 \%$ senyawa polifenol seperti katekin dan antosianin. Sebanyak $60 \%$ dari total fenolik pada biji kakao mentah adalah monomer flavanol (epikatekin dan katekin) dan oligomer proanidin (dimer hingga dekamer).

\section{Residu Pestisida}

Salah satu dampak negatif
penggunaan pestisida yang kurang bijaksana adalah bahaya adanya residu pestisida pada produk tanaman yang dilindungi maupun pada lingkungan sekitar. Produk tanaman kakao Indonesia, biji keringnya digunakan sebagai bahan baku untuk menghasilkan produk hilir dengan 
berbagai varian maupun produk antara (intermediate products), sebagian besar diekspor ke negara-negara maju. Negara pengimpor biji kakao umumnya sangat peduli terhadap aspek kesehatan maupun lingkungan. Oleh karena itu adanya residu bahan berbahaya sangat diperhatikan (Wiryadiputra, S.,2013).

Parameter residu pestisida pada kakao bubuk yang dianalisis dapat dilihat pada Tabel 2.

Tabel 2. Hasil Analisa Residu Pestisida kakao bubuk

\begin{tabular}{lcc}
\hline \multicolumn{1}{c}{$\begin{array}{c}\text { Parameter } \\
\text { Residu Pestisida }\end{array}$} & $\begin{array}{c}\text { Kakao Bubuk } \\
\text { (BS) }\end{array}$ & Kakao Bubuk (BTS) \\
\hline Organoklorin & & \\
Lindan & Ttd & Ttd \\
Dieldrin & Ttd & Ttd \\
Heptaklor Ep & Ttd & Ttd \\
DDT & Ttd & Ttd \\
Endrin & Ttd & Ttd \\
Endosulfan & Ttd & Ttd \\
Organofosfat & & \\
Diazinon & Ttd & Ttd \\
Metidation & Ttd & Ttd \\
Klorpirifos & Ttd & Ttd \\
Malation & Ttd & Ttd \\
Fenitrition & Ttd & Ttd \\
Profenofos & Ttd & Ttd \\
Monokrotofos & Ttd & Ttd \\
Piretroid & & \\
Permetrin & Ttd & Ttd \\
Sipermetrin & Ttd & Ttd \\
Deltametrin & Ttd & Ttd \\
\hline
\end{tabular}

\section{SIMPULAN}

Kakao bubuk yang dihasilkan dari biji kakao sangrai (BS) dengan uap air panas mempunyai kandungan senyawa total polifenol $6,89 \%$ sedangkan kakao bubuk tanpa sangrai (BTS) mempunyai kandungan total polifenol $9,42 \%$. Senyawa katekin pada kakao bubuk dari biji kakao sangrai (BS) $6,335 \mathrm{~g} / 100 \mathrm{~g}$, dan dari biji kakao tidak sangrai (BTS) 6,626 g/100g. Sedangkan residu pestisida dari semua parameter yang dianalisa tidak ada yang terdeteksi sehingga kakao bubuk yang dihasilkan aman dari pestisida.

\section{DAFTAR PUSTAKA}

1. Barberan, F.A.T; Jovellanos, E.C; Marin, A; Muguerza, B; izquierdo, A.G; Cerda, B; Zafrilla, P; Morillas, J; mulero, J; Ibarra, A; Pasamar, M.A; Ramon, D;
Espin, J.C. 2007. A New Process To Develop a Cocoa Powder with Higher Flavonoid Monomer Content and Enhanced Bioavailability in Healthy Humans. J. Agric. Food Chem, 55, 3926-3935.

2. Cooper, K.A., E. Campos-Gimenez, D.J. Alvarez, K. Nagy, J.L. Donovan and G. Williamson. 2007. Rapid reversed phase ultra-performance liquid chromatography analysis of the major cocoa polyphenols and interrelationships of their concentrations in chocolate. Journal of Agricultural and Food Chemistry 55 : 2841-2847.

3. Crozier, S.J., A.G. Preston, J.W. Hurst, M.J. Payne, J. Mann, L. Hainly and D.L. Miller. 2011. Cocoa seeds are a "Super Fruit" : A comparative analysis of various fruit powders and products. 
Chemistry Central Journal 5 : 1-6. SIRINOV

4. Gu, L., S.E. House, X. Wu, B. Ou and R.L. Prior. 2006. Procyanidin and catechin contents and antioxidant capacity of cocoa and chocolate products. Journal of Agricultural and Food Chemistry 54 (11) : 4057-4061.

5. Harrington, W.L. 2011. The Effects of Roasting Time and Temperature on The Antioxidant Capacity of Cocoa from Dominican Republic, Equador, Haiti, Indonesia and Ivory Coast. Thesis of Master of Science The University of Tennessee, Knoxville USA. $66 \mathrm{p}$

6. Hui, Y.H. 1996. Bailey's Industrial Oil and Fat Products. Vol. 2. Edible Oil and Fat Products: Oil and Oil Seeds. Pp 241-270. New York: John Wiley and Sons, Inc.

7. Khan et al. 2014. Cocoa Polyphenols and Inflammatory Markers of Cardiovascular Disease. Nutrients. 6, 844-880.

8. Kusuma, Y.T.C., S, Suwasono.S, Yuwanti. 2013. Pemanfaatan biji kakao inferior campuran sebagai sumber anti oksidan dan antibakteri. Berkala ilmiah Pertanian 1(2): 33-37.

9. Misnawi. 2005. Peranan Pengolahan Terhadap Pembentukan Citarasa Cokelat. Warta Pusat Penelitian Kopi dan Kakao. 21:3.

10. Nazaruddin, R., Seng L, Hassan, O., dan Said M, 2006. Effect of pulp pre-conditioning on the content of polyphenols in cocoa beans (Theobroma cacao) during fermentation industrial crops and products, 24: $87-94$.

11. Nestle Research Centers. 2010. Focos on: Polyphenols in chocolate. Nestle Research Centers. 3p.
12. Oracz, J. and Nebesny, E. 2016. Antioxidant properties of cocoa beans (Theobroma cacao L.): Influence of cultivar and roasting conditions. International Journal of Food Properties. 19 (6): 1242-1258.

13. Ramlah, S., 2014. Pengaruh Suhu Penyangraian Terhadap Mutu Cokelat sebagai Makanan Kesehatan Penurun Kadar Kolesterol Darah. Jurnal Industri Hasil Perkebunan, Vol 9 No.2, Hal. 115-124. BBIHP Makassar

14. Rosniati, Kalsum. 2018. Pengolahan Kakao Bubuk Dari Biji Kakao Nonfermentasi dan Tanpa Fermentasi Sebagai Sediaan Bahan Pangan Fungsional. Jurnal Industri Hasil Perkebunan, Vol 13 No.2, Hal. 107116. BBIHP Makassar

15. Sianturi, G., 2003. Cokelat Cegah Kanker, Stroke, dan PJK. http:/www. kompas.co.id/ kesehatan/ news/ senior/gizi/0304/24/gizi.

16. Suazo, Y., Davidov-Pardo, G. and Arozarena, I. 2013. Effect of Fermentation and Roasting on The Phenolic Concentration and Antioxidant Activity of Cocoa From Nicaragua. Journal of Food Quality. 37: 50-56.

17. Wiryadiputra, S., 2013. Residu Pestisida Pada Biji Kakao Indonesia Dan Produk Variannya, Serta Upaya Penanggulangannya. Review Penelitian Kopi dan Kakao 1 (1) 2013, 39-61.

18. Yuliatmoko, W., 2008. Efek Konsumsi Minuman Kakao bubuk Lindak Bebas Lemak Terhadap Aktivitas Antioksidan Flavonoid pada Plasma Manusia. Jurnal Matematika, Sains dan Teknologi, Vol.9 No.2, hal. 102113. 